\title{
Cross-Cultural Psychiatry and Implications in Education
}

\author{
Iverson C. Bell Jr. ${ }^{1}$
}

Received: 29 June 2015 / Accepted: 14 October 2015 / Published online: 27 October 2015

(C) Academic Psychiatry 2015

To the Editor:

There have been incremental improvements in addressing color-based racism, but current events have emphasized the ongoing problems. Psychiatric education addresses the issues of cultural differences. The Accreditation Council for Graduate Medical Education (ACGME) Milestones [1] identify this specific need for cultural empathy and the necessary understanding of cross-cultural (or transcultural) issues. Cultural empathy has now become part of the standards woven throughout the "milestones" of psychiatric training.

The current political atmosphere has highlighted ethnic and racial differences and given some pseudo-validity to those embittered by change. Much of this country is involved in various multifactorial debates involving immigration, race, sexual orientation, abortion, etc. Psychiatric educators are in the position to insure that trainees are familiar with various cultures and cognizant of how each culture interacts with the other in order to be more empathic.

It would be extremely difficult, if not impossible, to educate one toward achieving an understanding of these issues without giving examples in therapy supervision. Perhaps, we should consider teaching by example (our oft maligned but valid apprenticeship model $[2,3]$. Many in the lay community are familiar with Jewish/Christian, Jewish/Muslim, and Christian/Muslim group activities that educate about the similarities and differences in the "other's" values and lifestyle [4].

Iverson C. Bell, Jr.

ibell@uthsc.edu

1 Department of Psychiatry, University of Tennessee Health Science Center College of Medicine, Memphis, TN, USA
Our residency educational system uses texts and papers to educate about, and psychiatric supervision to illustrate these differences and how to address them. Unlike the layperson examples, however, this is not done on an equal cultural footing. We assume ourselves to be able to understand our own prejudices and prevent their interference in teaching and treating. To be aware of and react appropriately to this possible countertransference, one must be aware of it. Our resident education must address this.

It is possible that research into working with cross-cultural groups will serve the purpose of this education. I propose that research into working with cross-cultural groups be evaluated for usefulness and efficacy in psychiatric training.

\section{References}

1. The Psychiatry Milestone Project. The Accreditation Council for Graduate Medical Education and the American Board of Psychiatry and Neurology. 2013.

2. Stalmeijer RE et al. Cognitive apprenticeship in clinical practice: can it stimulate learning in the opinion of students? Adv Health Sci Educ Theory Pract. 2009;14(4):535-46.

3. Tim D. Osler, Flexner, apprenticeship and 'the new medical education'. J R Soc Med. 2005;98(3):91-5.

4. Beyond tolerance: searching for interfaith understanding in America, Gustav Niebuhr, Penguin Group 2008 